\title{
Reply to Letter to the Editor: Mean Platelet Volume may not be A Diagnostic Marker for Hepatocellular Carcinoma due to Chronic Hepatitis C Infection
}

\author{
Maha Z. Omar ${ }^{1}$, Mohebat H. Gouda ${ }^{2}$, Mona M. Elbehisy ${ }^{3}$ \\ ${ }^{1}$ Department of Hepatology, Gastroenterology and Infectious Diseases, faculty of Medicine, \\ Benha University , Egypt \\ ${ }^{2}$ Department of Pathology, Faculty of Medicine, Benha University, Egypt \\ ${ }^{3}$ Department of Clinical Pathology, faculty of Medicine, Benha University , Egypt
}

Corresponding Author Maha Z. Omar

Mobile:

$+01223287312$

\section{E mail:}

mahazeinelabedin@ya hoo.com

Key words:

$M P V, M P V / P C, A F P$, $\mathrm{HCC}$
We would like to thank Beyan and Beyan [1] for their interest in our article [2] and for their comments on this article. They stated that mean platelet volume (MPV) can be affected by many factors including time of analysis after venipuncture, methods of analysis, anticoagulant used and specimen storage temperature [3.4]. I do agree that there should be more details for this part in our study, but all MPV values were measured in dipotassium EDITA tubes within $1^{\text {st }}$ hour after venipuncture, there was no different approach in MPV measurement between our patients and controls therefore, we don't believe this factor significantly influenced our results.
It's true that MPV is affected by age and sex in some studies and not in other studies [3] as prof/ Beyan and prof/ Beyan mentioned in their comments, but we adjust the age and sex mismatch in our study by using logistic analysis and found that MPV still independent predictor for HCC. In our study, MPV was less sensitive and less specific than AFP in diagnosis of HCC. So in conclusion MPV can be studied as an added marker for AFP to increase its specificity and sensitivity in diagnosis of HCC. However it can't be replace the role of AFP in diagnosis. Further studies are needed in this area.

\section{REFERENCES}

1. Beyan C, Beyan E. Mean platelet volume may not be a diagnostic marker for hepatocellular carcinoma due to chronic hepatitis $\mathrm{C}$ infection. Afro-Egypt $J$ Infect Endem Dis 2018;8(2): 105-106.

2. Omar MZ, Gouda MH, Elbehisy MM. Mean platelet volume and mean platelet volume/platelet count ratio as diagnostic markers for hepatocellular carcinoma in chronic hepatitis $\mathrm{C}$ patients. Afro-Egypt J Infect Endem Dis 2018; 8(1): 15-23.

3. Noris P, Melazzini F, Balduini CL. New roles for mean platelet volume measurement in the clinical practice? Platelets 2016; 27(7): 607-612.

4. Jackson SR, Carter JM. Platelet volume: laboratory measurement and clinical application. Blood Rev 1993; 7(2): 104-113. 